\title{
Trigeminal Neuralgia
}

\author{
Kandasamy Ganesan and Asha Thomson
}

\subsection{Introduction}

Neuralgia can be defined as paroxysmal, intense intermittent pain that is usually confined to specific nerve branches of the head and neck. The trigeminal nerve is responsible for sensory innervation of the scalp, face and mouth, and damage or disease to this nerve may result in sensory loss and/or pain. Trigeminal Neuralgia (TN), also referred to as 'Tic Douloureux,' is sought to be the most intense and wellknown neuralgias, which displays classical features of intense sharp, stabbing sensations with or without burning pain throughout the face. It is considered as one of the most chronic painful conditions known within the body. The pain, which is often initiated by just a light touch to an area of skin, can occur at any time without warning and depending on the severity of the condition, the frequency of the attacks can vary.

This severe medical condition affects one or more branches of the fifth cranial nerve known as the trigeminal nerve, which is the largest cranial nerve and has both sensory and motor functions. $>85 \%$ of cases of trigeminal neuralgia are of the classic type known as classical trigeminal neuralgia (CTN), while the remaining cases can be separated to secondary trigeminal neuralgia (STN). STN is thought to be

Electronic Supplementary Material The online version of this chapter (https://doi.org/10.1007/978-981-15-1346-6_26) contains supplementary material, which is available to authorized users.

K. Ganesan $(\square)$

Department of Oral and Maxillofacial Surgery, Southend

University Hospitals NHS Trust, Southend-on-Sea, UK

University of Leeds, Leeds, UK

e-mail: mailme@kandyganesan.com

A. Thomson $(\bowtie)$

Norfolk and Norwich University Hospitals, Norfolk, UK

e-mail: ashathomson1@nhs.net initiated by multiple sclerosis or a space-occupying lesion affecting the trigeminal nerve, whereas the leading cause of CTN is known to be compression of the trigeminal nerve in the region of the dorsal root entry zone by a blood vessel.

Investigation of the cause of the neuralgia present and treatment planning of these symptoms can pose a challenge for any clinician and the importance of detailed assessment and history taking of orofacial pain should be highlighted. Extreme care must be taken to identify the underlying cause of the symptoms experienced by the patient, who may often present in distress, as suffering from head and neck neuralgia can severely affect a patient's quality of life.

There is no guaranteed cure for the condition of trigeminal neuralgia, but there are several treatment options that may give symptomatic relief. In this chapter, we will review the common neuralgias occurring within the oral and maxillofacial region with specific emphasis on trigeminal neuralgia. We will discuss the historical evolution of treatment including the medical and surgical modalities with the use of current literature and newer developments. This highlights the need for further studies and investigation into the phenomenon of neuralgia to improve patient management and treatment outcomes.

This chapter will also cover surgical interventions such as, peripheral neurectomies, which can be done by an Oral and Maxillofacial Surgeon.

\subsection{Anatomy of the Trigeminal Nerve}

This is the largest cranial nerve with both sensory and motor components. It provides sensory nerve supply to the face, the scalp, the nasal cavity and the oral cavity including the teeth. It carries proprioception from the periodontal ligaments of the teeth and masticatory muscles. The trigeminal nerve provides motor supply to the muscles of mastication, tensor tympani, tensor veli palatini, mylohyoid and anterior belly of digastric. Its name is derived from its three main 
Fig. 26.1 Schematic diagram showing the Meckel's cave within the dura layer lateral to cavernous sinus

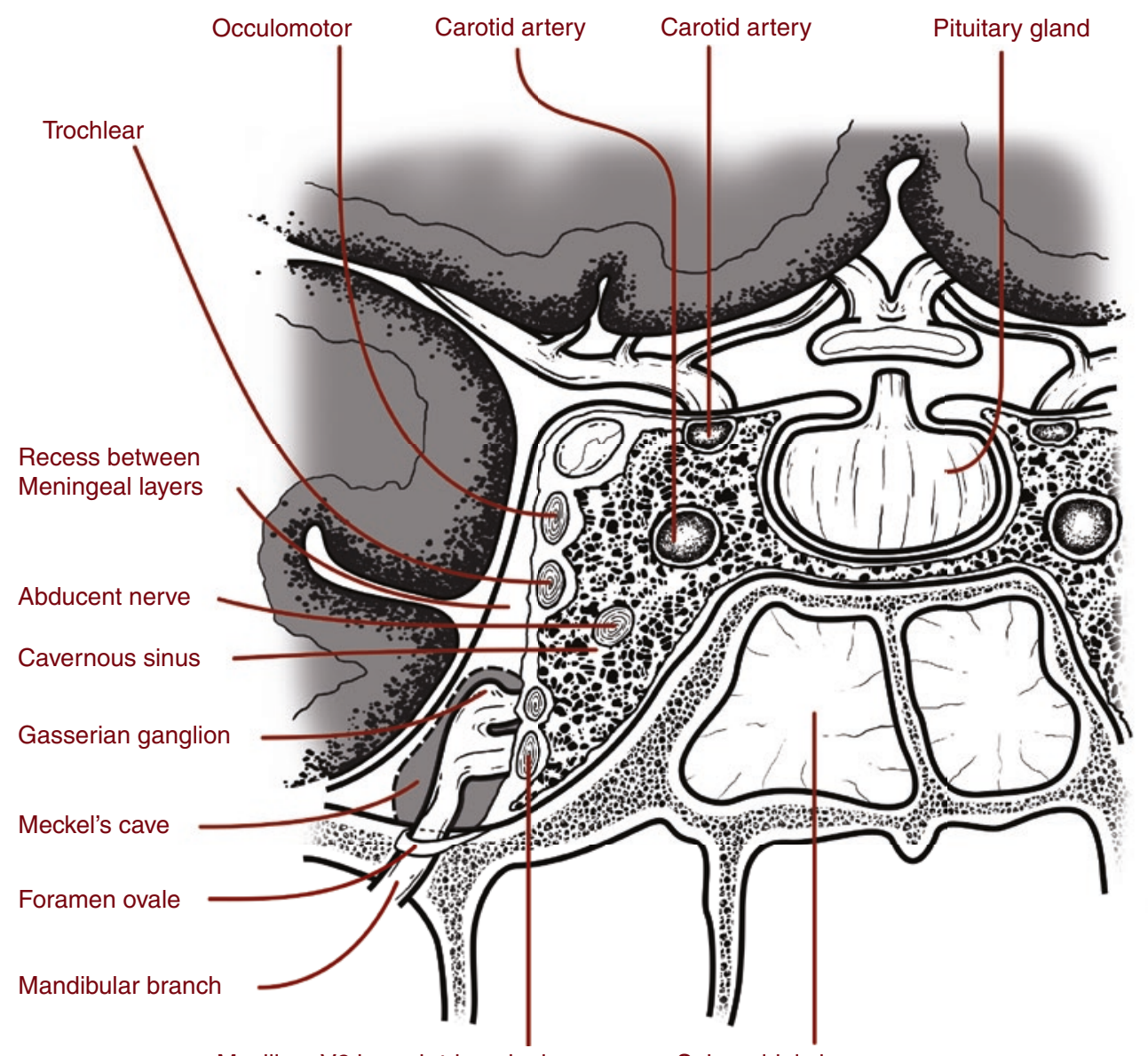

Maxillary V2 branch trigeminal

(C)Association of Oral and Maxillofacial Surgeons of India branches ophthalmic, maxillary and mandibular. This nerve can be divided into various anatomical segments by its course from the brain stem, cisternal, Meckel's cave, ganglionic and finally to peripheral divisions (Ophthalmic, maxillary and mandibular). For trigeminal neuralgia, understanding of the anatomy of cisternal and Meckel's cave segments is important.

The trigeminal ganglion is located in the Meckel's cave, which is a recess between the two layers of the dura in the posteromedial portion of the middle cranial fossa. Any disease process in and around the Meckel's cave can develop the symptoms of trigeminal neuralgia. The anatomy of the Meckel's cave is detailed through the use of Fig. 26.1.

Arachnoid membrane from the posterior cranial fossa extends into the Meckel's cave and continues along the rootlets of the trigeminal nerve to as far as the trigeminal ganglion [1].

\subsubsection{Peripheral Distribution of Trigeminal Nerve (Fig. 26.2 and Table 26.1)}

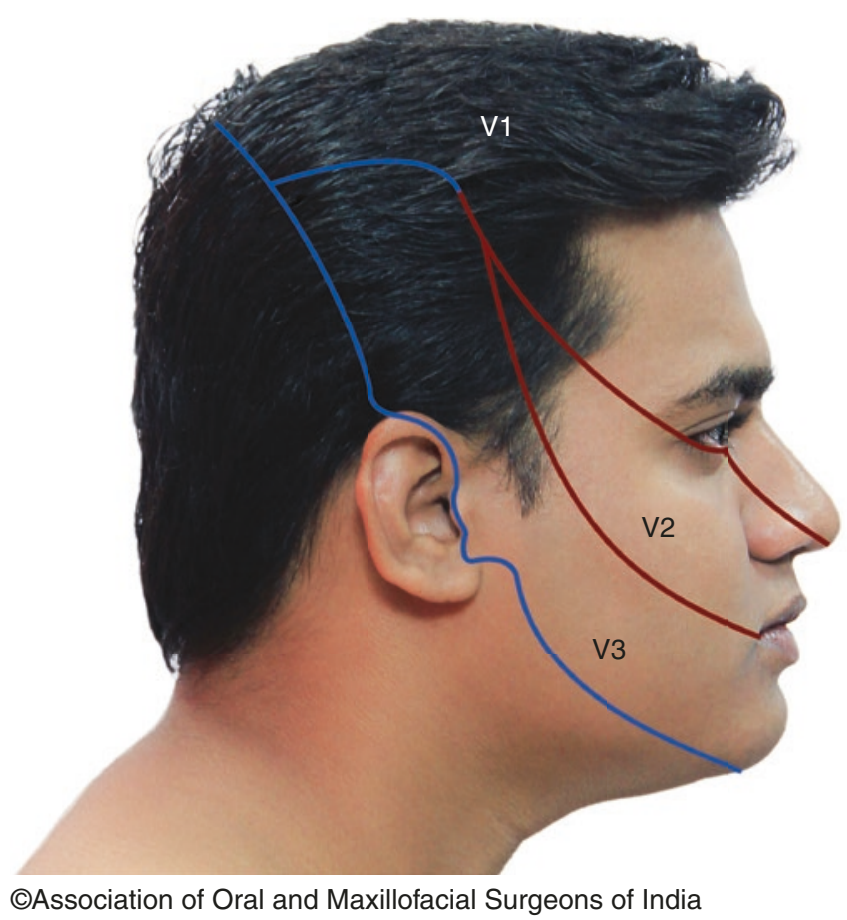

Fig. 26.2 Diagram showing peripheral distribution of trigeminal nerve 
Table 26.1 Branches of the 3 divisions of the trigeminal nerve

\begin{tabular}{|c|c|}
\hline Nerve & Branches \\
\hline \multicolumn{2}{|l|}{ V1-Opthalmic } \\
\hline 1. Frontal nerve & $\begin{array}{l}\text { a. Supraorbital nerve } \\
\text { b. Supratrochlear nerve }\end{array}$ \\
\hline \multicolumn{2}{|l|}{ 2. Lacrimal nerve } \\
\hline 3. Nasociliary nerve & $\begin{array}{l}\text { a. Long Ciliary nerve } \\
\text { b. Anterior and Posterior } \\
\text { Ethmoidal nerves } \\
\text { c. Infratrochlear nerve }\end{array}$ \\
\hline \multicolumn{2}{|l|}{ V2-Maxillary } \\
\hline \multicolumn{2}{|l|}{ 1. Meningeal Branches } \\
\hline 2. Ganglionic Branches & $\begin{array}{l}\text { a. Greater Palatine nerve } \\
\text { b. Lesser Palatine nerve } \\
\text { c. Nasopalatine nerve } \\
\text { d. Nasal Branches }\end{array}$ \\
\hline $\begin{array}{l}\text { 3. Posterior Superioer Alveolar } \\
\text { nerve }\end{array}$ & \\
\hline 4. Infraorbital nerve & $\begin{array}{l}\text { a. Anterior Superior Alveolar } \\
\text { nerve } \\
\text { b. Middle Superior Alveolar } \\
\text { nerve }\end{array}$ \\
\hline 5. Zygomatic nerve & $\begin{array}{l}\text { a. Zygomaticofacial nerve } \\
\text { b. Zygomaticotemporal nerve }\end{array}$ \\
\hline V3-Mandibular & \\
\hline $\begin{array}{l}\text { 1. Nervous Spinosus } \\
\text { 2. Motor Branches }\end{array}$ & \\
\hline 3. Anterior Division & $\begin{array}{l}\text { a. Nerve to Lateral Pterygoid } \\
\text { b. Masseteric nerve } \\
\text { c. Deep Temporal nerve } \\
\text { d. Buccal nerve }\end{array}$ \\
\hline 4. Posterior Division & $\begin{array}{l}\text { a. Auriculotemporal nerve } \\
\text { b. Lingual nerve } \\
\text { c. Inferior Alveolar nerve } \\
\text { i. Nerve to Mylohyoid } \\
\text { ii. Mental nerve }\end{array}$ \\
\hline
\end{tabular}

\subsection{Aetiology of Trigeminal Neuralgia}

\subsubsection{Neurovascular Compression}

Myelin sheath surrounds the cranial nerves formed by oligodendrocytes in the central nervous system and Schwann cells in the peripheral nervous system. The main function of the myelin sheath is to provide mechanical insulation and metabolic support for the axons. This myelin sheath at the transition zone (TZ), between the central and peripheral nervous systems is a vulnerable area in the context of neurovascular compressions. The TZ is more relevant and not always located in the same position as root entry zone (REZ) [2].

Neurovascular compression at the REZ is found to be a reason for $80 \%$ of the $\mathrm{TN}$ but not a consistent finding in all the TN patients. This neurovascular contact at the REZ is also found in non-TN patients. A superior cerebellar artery alone or in association with another vessel is found in $88 \%$ as a source for vascular compression. Other vessels such as anterior cerebellar artery, the basilar artery and vertebral artery are also found to be in contact with RTZ [3].

\subsubsection{Multiple Sclerosis (MS)}

In 1950, the first finding of a connection with multiple sclerosis is reported [4]. A comprehensive review of pain in MS patients identified the prevalence to be $\mathrm{TN}$ to be $3.8 \%$, which is lower than headaches $(43 \%)$ and neuropathic extremity pain (26\%) [5].

From this review, TN was the first symptom of MS in 9-14\% of patients and the mean age of onset ranged from 33 to 51 , highlighting younger patients than patients with $\mathrm{TN}$ alone. In addition to this, TN due to MS is often associated with numbness and paraesthesia [6]. Neuralgic pain, over a period of time, evolves with atypical features and involves an increase in the number of divisions of trigeminal distribution. Additionally, $6 \%$ became bilateral and literature shows MS precedes TN, however several studies showed TN as a first symptom before any other MS symptom $[7,8]$.

Electrophysiologic testing of MS-related TN patients showed up to $89 \%$ abnormal trigeminal reflexes such as the blink reflex compared to $3 \%$ in idiopathic TN patients. In MS, plaques result in neural damage causing TN but not as a result of neurovascular compression however, both can play a role in the aetiology of TN [9].

In MS, ephaptic nerve conduction is effected due to an increase in inflammatory activity in the plaques with a high T-cell activity [10].

\subsubsection{Tumour and Cyst}

Tumours alone are shown to be aetiology in $\mathrm{TN}$ from 0.8 to $11.6 \%$, but this increased to 5.7 to $13.4 \%$ when aneurysms, angiomas or vascular malformations are present. Tumours may cause $\mathrm{TN}$ by compression, wrapping around the nerve root, neurovascular compression and/or neoplastic factorrelated chemical irritation [6].

\subsubsection{Diabetes Mellitus}

The involvement of diabetic neuropathy is more common in the 3rd, 4th and 6th cranial nerves than in the trigeminal nerve. Diabetic patients tend to have more of a neuropathic pain than neuralgic pain, which may present as hot, burning, electric with a pins and needles sensation, especially in the peripheral areas such as the hands and legs. Often, this tends to be bilateral, and may present worse at night [11].

Hyperglycaemia is known to cause aggravated nerve damage, and this also applies for the increased risk of developing TN however, more studies need to be done in order to validate the underlying pathophysiology between the association of diabetes and TN [12]. 


\subsubsection{Herpes Simplex}

Post-herpetic TN after herpes zoster-shingles has been documented [13] and can present as a burning persistent severe pain for the patients. The reactivation of the latent herpes zoster virus from the dorsal root ganglion results in TN affecting the ophthalmic branch in over $80 \%$ of cases. When antivirals are administered within $72 \mathrm{~h}$ from the onset of the rash, they are known to reduce the duration of the rash, pain and also the incidence of post-herpetic neuralgia [14-17].

\subsection{Pathophysiology of TN}

The exact aetiopathogenesis of TN remains unclear. The most common hypothesis is the "ignition theory," which is a result of abnormalities in the afferent neurones of the trigeminal root or ganglion. Injury to the axons can make them hyperexcitable and also cause central sensitisation, leading to TN [18].

Demyelination at the trigeminal REZ where central and peripheral myelin meets results in generation of ectopic impulses. This in turn can cause cross-talk between touch and pain sensations which is thought to decrease the central pain gating mechanisms. Which, can conversely result in trigeminal nerve remyelination. This may explain the spontaneous remission in some patients; however, the same cannot be applied for rapid electrophysiologic recovery and pain relief after microvascular decompression treatment [6].

The affected (demyelinated) nerves can spontaneously discharge electric impulses. Touch sensation carrying A- $\beta$ fibres aligned near the pain carrying (nociceptive pathway) $A-\delta$ and $C$ fibres in the REZ, leading to ephaptic cross-talk between the two pathways. This may explain how trivial touch sensation triggers pain in TN [18].

The trigeminal ganglion itself can show pathological changes such as hypermyelination [19, 20]. Demyelination is common in many patients with TN and is caused by a compression by vascular structures, MS, tumours and vascular malformations.

Compression on the REZ should cause a continuous pain, but TN patients suffer paroxysmal attacks, which are most likely to be caused by spontaneous discharges where the threshold for the repetitive firing has been altered. It is also notable in TN that such firing occurs not only spontaneously but also by trivial tactile stimuli. This type of firing behaviour is also observed within in dorsal root ganglions [20].

Rappaport and Devor [21] explained that the development of atypical features of the TN may be due to central sensitization following a prolonged barrage of nerve impulses and also from progressive damage to trigeminal afferents, which become the source of continuous ectopic discharges [20].

Interestingly, literature shows that different treatments of TN yield similar results in pain control however, the long- term results show that decompression provides prolonged pain relief compared to destructive peripheral procedures [20]. In addition, destructive procedures may cause some degree of sensory loss along with the same duration of pain relief [22].

\subsection{Historical Perspective}

Historically, reviews dating back to $2 \mathrm{AD}$ demonstrates the existence of TN or a similar condition described by Aretaeus of Cappadocia, a contemporary of Galen. The same author is known for the description of migraine, and in the 11th century [23], an Arab physician Jujani describes a unilateral facial pain causing spasms and anxiety. He explains that the cause of the pain is 'proximity of the artery to the nerve' [24].

Wells Cathedral, an Anglican cathedral in Wells, Somerset, England, dedicated to St Andrew the Apostle, contains the tomb of Bishop Button, who died in 1274. He was canonized, and many pilgrims and toothache sufferers left offerings at the tomb, in commemoration of which the capitals of the pillars bear carvings of people depicted with facial neuralgia. One is famed as the toothache figure and because of the surprising rarity of dental caries at that time (confirmed when the sarcophagus was opened in 1848), Wilfred Harris pointed out the probable relevance to trigeminal neuralgia [25].

A first Royal account in relation to TN is by John Locke, the famous philosopher and physician who wrote a series of letters to Dr John Mapletoft in 1677 [26] describing TN suffered by Countess of Northumberland, wife of Ambassador to France.

Nicolas Andre invented the term tic douloureux in 1756 in a book, Observations pratiques sur les maladies de l'urethre et surplusiers faits convulsifs [27].

John Fothergill publishes the first account of TN to the Medical Society in London in 1773 and described TN as a 'paroxysmal unilateral facial pain, evoked by eating, speaking or touching, starting and ending abruptly, and associated the condition with anxiety [23].

Between the eighteenth and nineteenth centuries, Pujol, Chapman and Tiffany completed the clinical picture and differentiated TN from other facial pain conditions. Later, Oppenheim highlighted the association between TN and MS [28].

Treatment of TN including microvascular decompression has been available since 1925 [29]; however, it took another 50 years to become an accepted neurosurgical intervention. During 1950 to 60, Gardner and Miklos [30] promoted neurovascular decompression theory and continued to modify the technique, but a major shift in this practice happened after a large clinical series published by Jannetta [31]. Throughout the last century, ablative neurosurgical procedures continued to evolve to balance 
the best possible outcome between pain control and adverse effects. The latest in this process is radiosurgery. And even although surgical practice was continuing to evolve, medical therapy had little success in the same period. In 1942, Bergouignan's discovery of phenytoin was the first medical intervention in effective control of pain paroxysms [32]. In 1953, Walter Schindler discovered Carbamazepine and marketing was started in 1962. Although it was originally used for epilepsy, trials showed their effectiveness in TN pain control.

\subsection{Clinical Presentation}

Within the maxillofacial region, neuralgias can present in different severities and can affect patients from any race, gender and age. Certain conditions may be distinctive to certain groups of people, but there is no current classification followed for the diagnosis and management of neuralgic pain; however, groups do exist in order to distinguish the categories that they may be separated into.

These pain episodes experienced may last from seconds up to several minutes and can be described by the patient as an 'electric shock' feeling. This sensation may occur frequently per day (up to hundreds of times) over weeks and months and then suddenly stop with pain-free periods in between. It may also present infrequently with periods of remission, which may possibly last for years [13]. The pain often occurs unilaterally, does not usually cross the midline of the face and is often unbearable for the patient. It has been shown that only $3 \%$ of cases are known to be bilateral in nature [13].

\subsubsection{Risk Factors}

\section{Sex}

It has been highlighted that $\mathrm{TN}$ affects females more than males [13].

\section{Age}

In patients over 80 years old, males tend to have a higher incidence $(45 / 100,000)$ [13, 33-36].

It can be prominent within all age ranges, but most frequently, TN affects individuals over the age of 50 . Approximately $70 \%$ of the patients develop TN after they reach 60 years of age and it is known that the incidence of TN increases with age, and has been emphasised that this condition is rare to affect people younger than 40 years old $[36,37]$. This is therefore highly important in suggesting that multiple sclerosis may be present in younger patients who suffer from TN [38].

\subsubsection{Initiating Factors}

The pain felt can be precipitated by trigger areas or factors of light touch on specific areas of the face, and patients often avoid these actions, which they may feel causes the attacks.

These activities may include:

Shaving

Applying make-up or face cream

Brushing the teeth

Speaking

Smiling

Yawning

Face washing

Swallowing

Vibration

Exposure to cold such as cold wind, breeze on the face or air conditioning

Eating, chewing or biting into something

Touching or washing certain areas of the face

\subsubsection{Prevalence}

A systematic review highlighted that the range of TN prevalence was $0.03-0.3 \%$, mostly women were affected, and the affected age range was 37-67 years old. The affliction was marked by unilateral symptoms, most commonly in the maxillary and mandibular branches [39].

NICE guideline data and studies [13] indicate that a survey carried out within general practice in the United Kingdom, which highlighted that the annual incidence of trigeminal neuralgia was 8 per 10,000 .

The true prevalence of this condition remains unclear as there is little data to support the evidence of how common this condition is [13]. It is evident that even with studies carried out, further research is required to validate the prevalence of trigeminal neuralgia due to the complexity of the condition including diagnosis difficulties and heterogeneity of the disease characteristics [39].

\subsubsection{Clinical Diagnosis}

\subsubsection{Pain History}

Accurate diagnosis relies greatly on a detailed history of symptoms from the patient, with pattern and nature of the pain highlighting the condition as there is no definitive diagnostic test yet available. SOCRATES is a useful assessment tool (Table 26.2), which is often used to help clinicians in achieving an accurate pain history. 


\begin{tabular}{l|l|l|}
\hline $\begin{array}{l}\text { Table 26.2 SOCRATES assessment tool } \\
\text { Site/localization }\end{array}$ & $\begin{array}{l}\text { Can the pain be localized to a specific area? } \\
\text { Onset }\end{array}$ & $\begin{array}{l}\text { Sudden or gradual? when-day/night/ } \\
\text { spontaneous? }\end{array}$ \\
\hline $\begin{array}{l}\text { Characteristic of pain } \\
\text { Radiation }\end{array}$ & $\begin{array}{l}\text { Sharp, stabbing and dull ache } \\
\text { Does the pain radiate elsewhere? }\end{array}$ \\
\hline $\begin{array}{l}\text { Associated signs and } \\
\text { symptoms }\end{array}$ & Any associated signs or symptoms? \\
\hline Timing/duration & $\begin{array}{l}\text { Seconds/minutes/hours? (constant, } \\
\text { paroxysmal-recurrent and slowly/rapidly } \\
\text { progressive) }\end{array}$ \\
\hline $\begin{array}{l}\text { Exacerbating or } \\
\text { relieving factors }\end{array}$ & Does anything make it better/worse? \\
\hline Severity & How intense is the pain? Scale 1-10 \\
\hline
\end{tabular}

Trigeminal neuralgia may be misdiagnosed for dental pathology, and so it is important that unnecessary dental treatment is not carried out without full investigation of the source of the pain. When patients suffer from the condition, it often becomes apparent that their quality of life decreases as they may be unable to carry out their normal daily activities and suffer from weight loss due to problems in eating, and as a result the condition may lead to depression and/or isolation.

On clinical examination, trigeminal reflex testing may be used to test all three divisions of the nerve and may reveal loss of sensitivity in the cutaneous region, which may be related to the affected nerve. This may present as partial numbness (hypoesthesia) or complete numbness (anaesthesia) and occasionally may present as hyperaesthesia causing considerable discomfort.

The classical symptoms of trigeminal neuralgia are as follows:

- Severe shooting or stabbing pain, which may feel like an 'electric shock' on a focussed part or wider area of the face.

- Pain usually only affects one side of the face at one time.

- Bouts of pain may last from a few seconds to several minutes.

- Spontaneous attacks of pain may occur with or without triggers.

- As time progresses, the painful attacks may increase in frequency and intensity.

\subsubsection{Other Causes}

Trigeminal neuralgia can occur as a result of several causes such as trauma, tumours, infectious or demyelinating diseases, connective tissue diseases and can also be idiopathic in nature. This poses a challenge to the clinician when trying to investigate the cause of the pain. The importance of the causative factors may highlight the possibility that trigeminal neuralgia can present as the first manifestation of an underlying systemic disease. This emphasises that careful and in-depth investigations with detailed history taking are required in order to appropriately treat this life-affecting condition. A referral to a specialist in pain management or neurologist should be considered in severe cases [13, 38].

As trigeminal neuralgia is uspected when a patient has severe and intense pain in the orofacial region, other reasons may need to be explored for patients who have physical signs of motor or sensory problems. Neoplasms, infective conditions such as HIV, multiple sclerosis and even cerebrovascular disease may cause neuralgic pain, and so it is important to be aware of the differential diagnosis that could be derived from neuralgia within the head and neck.

$\mathrm{TN}$ is restricted to one or more branches of the trigeminal nerve distribution with an exception of TN in MS patients, where one side of the face may be affected. It is sudden in onset and typically lasts for a few seconds to a maximum of 2 min. Pain can be spontaneous but can also be triggered by innocuous mechanical stimuli or facial movements. In between the episodes, patients can remain pain-free and very rarely, patients suffer continuous pain in $\mathrm{TN}$.

\subsubsection{Glossopharyngeal Neuralgia}

Glossopharyngeal neuralgia (GPN) is a rare uncommon painful neuralgic condition involving pharyngeal/orofacial region including the ear, base of the tongue, tonsillar fossa and submandibular region. It has similar etiopathogenesis to TN with neurovascular compression and demyelination of the 9 th or the 10th cranial nerves. The prevalence rate is $0.2-$ 0.7 per 100,000 and accounts for $0.2-1.3 \%$ of the orofacial neuralgias [40].

Clinical history taking is important to differentiate different types of neuralgias. GPN clinically presents as a unilateral, severe and paroxysmal pain involving the ear, base of the tongue, tonsillar fossa and submandibular region. Painful symptoms are described very similar to TN symptoms such as, sharp, stabbing or electric shock like pain. Similar to TN, GPN is triggered by innocuous stimuli/function like swallowing, chewing, talking, coughing and yawning. 
According to the criteria put forward by the International Classification of headache disorders (ICHD) [41]:

- TN pain should be unilateral with at least three attacks

- Occurring in one or more divisions of the trigeminal nerve, with no radiation beyond the trigeminal distribution.

- Pain should have at least three of the following characteristics

- recurring in paroxysmal attacks lasting from a fraction of a second to $2 \mathrm{~min}$

- severe intensity

- electric shock-like, shooting, stabbing or sharp in quality

- precipitated by innocuous stimuli to the affected side of the face

- There should be no clinically evident neurological deficit

The International Association for the Study of Pain (IASP) current classification

Classical Caused by vascular compression of the trigeminal nerve TN root, resulting in morphological changes of the root

Secondary Caused by major neurological disease, e.g. a tumour of

TN the cerebellopontine angle (TN attributed to spaceoccupying lesions) or MS

Idiopathic No apparent cause

$\mathrm{TN}$

The readers may access the detailed classification at the following open access publication [42]. https://doi.org/10.1007/ s40265-018-0964-9.

\subsection{Investigations}

A thorough pain history and a clinical examination including cranial nerve examinations are important for the diagnosis of TN due to the fact that MS and tumours may be found in this cohort. Any deficiency in the cranial nerve examination, especially a sensory loss, should prompt further imaging.

In order to rule out possible diseases, specific tests may be carried out in adjunct by radiographic examinations such as plain radiographs including intra-oral (periapicals) and orthopantograms. These may be carried out in the first instance to rule out dental pathology, and orthopantograms may also be able to detect temporomandibular joint pathol- ogy. Cranial computed tomography scan (CT) may also be used in order to identify any changes of the maxillary sinus.

Magnetic resonance imaging (MRI) is an important investigation to investigate and to differentiate between patients suffering from trigeminal neuralgia due to tumours and MS [18]. It may demonstrate the close and potentially causative relationship between the trigeminal root and adjacent blood vessel and can be of specific value to exclude posterior cranial fossa lesions [38]. TN caused by MS should be ruled out, specifically in the younger patient, and this may be aided by MRI. Clinical Knowledge Summaries (CKS). NICE [13] guidelines recommend MRI assessment specifically for younger people, patients presenting atypical symptoms, nonresponders to initial therapy or anyone for whom neurosurgery is being considered. Even though MRI is commonly used, from previous studies carried out, the suggestion of its sensitivity and specificity seems to be variable [43-50]. As a result, emphasis is placed on the challenge in identifying the cause of trigeminal neuralgia as a relationship between the clinical symptoms and radiological findings as this may not be clear.

In idiopathic forms of trigeminal neuralgia, it is typical for no cause to be detected with the patient having both normal neurological and MRI examinations, which can cause difficulty with treatment planning. MRI finding of an aberrant loop of a blood vessel at RTZ is the most common cause, and this is reported in about $60-90 \%$ of the cases described in neurosurgical/neuroradiological series [51-54].

Meaney et al. have designed a set of specific parameters to visualise the blood vessels using thin slices to create the reconstruction of nerve and vessel in any orientation. This is called magnetic resonance tomographic angiography (MRTA) [55]. This reconstruction between the vessels and the nerves allowed us to identify the neurovascular compression. In comparison to MRTA, MR angiography only provides image of the blood vessels. Meaney et al. then validated their findings by comparing the MRTA findings with surgical findings. In a series of 52 consecutive cases, MRTA findings were comparable to surgical finding in 50 out of 52 cases. In four cases, MRTA misclassified veins as arteries; otherwise, MRTA is a sensitive and specific method in demonstrating neurovascular compression [44].

\subsection{Management}

\subsubsection{Medical Management}

It has been highlighted that first line of treatment for trigeminal neuralgia is still pharmacological treatment. The desired 
outcome of these patients is to treat the pain experienced, manage the symptoms and with time preferably, eradicate these symptoms in order to improve the patient's quality of life. Where appropriate, referral to a specialist pain service and/or neurologist may be necessary with clear information and given to the patient.

There are several drugs that have been delivered systemically or topically in the use of treating trigeminal neuralgia, which include:

Baclofen
Dextromethorphan
Lamotrigine
Gabapentin
Pregabalin
Sumatriptan
Levetiracetam
Eslicarbazepine
Pimozide
Proparacaine
Tizanidine
Tocainide
Topiramate

The most common therapy of choice is Carbamazepine for pain control [56] and after carrying out a systematic review of the literature, The American Academy of Neurology and the European Federation of Neurological Societies support Carbamazepine (200-1200 mg/day) [57] as the first-line treatment to be offered due to strong evidence supporting this pharmacological treatment. In addition to this, another drug of preferred choice is Oxcarbazepine (600-1800 mg/day) [57], which is known to have better tolerability and is also supported by existing guidelines [13, 58].

All the above drugs have been evaluated using RCTs, whereas other drugs such as capsaicin cream, phenytoin, clonazepam, gabapentin, oxcarbazepine, mexiletine and tramadol have been assessed from case reports and case series. Studies involving many of these drugs regarding the full benefit and effect on the treatment of trigeminal neuralgia are limited, and so further evaluation is required [59, 60]. The response to the drugs mentioned is unique to each patient, and it is evident that the doses also vary between patients in order to achieve a beneficial effect to counteract the symptoms experienced. It has been highlighted that it may be helpful for the patient to keep a pain diary in order to record episodes and help the patient and clinician identify possible trigger factors and timing of the pain. This may aid treatment planning and may give patients back a sense of control, which has been lost due to their condition.

\subsubsection{Carbamazepine and Oxcarbazepine}

Based on existing evidence, carbamazepine also known with the trade name 'Tegretol' is an anti-convulsant drug used primarily in the treatment of epilepsy [61] and remains the drug of choice for standard first-line treatment of trigeminal neuralgia in patients over 18 years of age $[13,57,58]$. It is considered to be of diagnostic help if complete resolution or reduction of symptoms occurs after its use [38]; however, carbamazepine must be used prophylactically and continuously for long periods, with tiered dosages prescribed to suit individual patients in regard to their response. Carbamazepine should be used with caution, and as it not an analgesic, it is not appropriate to use this medication during a pain episode for relief as it will not have an analgesic effect on symptoms. Patients can often misinterpret what the purpose of the medication is, and so this in turn highlights the importance of patient communication. The mechanism of the medication, the instructions in terms of dosage titration, timing of effects and the possible adverse side effects associated with its use should be highlighted. From current guidelines such asNICE [13], it has been advised that if no sinister or red flag symptoms are evident and carbamazepine is not contraindicated for the patient, then, the following dosage guideline can be offered:

- $100 \mathrm{mg}$ up to twice daily, titrated in increments of 100$200 \mathrm{mg}$ every 2 weeks until pain has been relieved

- $200 \mathrm{mg}$ three of four times daily (600-800 mg daily) is seen in the majority of people to be the dosage of choice sufficient to manage pain

- 1600 mg maximum dose daily

- Once pain is in remission, the dosage should be gradually reduced to the lowest possible maintenance level or even discontinued until a further episode occurs.

Frequent side effects have been reported with the use of carbamazepine drug therapy with specific emphasis on elderly patients [61-63]. When patients are treated with carbamazepine, it is strongly advised that a full blood count and liver function tests are carried out prior to starting treatment and then reviewed periodically in order to monitor the possible effects of the drug. Hyponatraemia, which refers to low sodium levels, is thought to occur in $20 \%$ of patients, and NICE guidelines [13] suggests that carbamazepine in concurrent use with sertraline can also increase this risk. Serum levels of the drug are not routinely monitored unless carbamazepine toxicity is suspected but within the $\backslash$ British National Formulary (BNF), all information is available in regard to drug interactions, adverse effects and contraindications and cautions. Within primary care settings, this is the standard first choice of treatment if the physician is confident with the diagnosis; otherwise, it is advised to refer the patient to a secondary care specialist for further investigations and treatment. 
In several studies, the effectiveness of carbamazepine was demonstrated with specific outcomes found in the reduction of both intensity and frequency of the painful paroxysms [36, 57, 64-68]. In addition to this, the pharmacological drug of choice was found to be equally effective on the reduction of both trigger touch and spontaneous attacks $[59,66]$. Due to the possible side effects from carbamazepine, oxcarbazepine may often be used as initial treatment due to the decreased potential drug interactions and possible greater tolerability acceptance $[57,63,68]$.

\subsubsection{Gabapentin}

It is known for its effective role in the management of neuropathic pain especially post-herpetic neuralgia, but there is a lack of evidence on its role in the management of TN. There is one randomized-controlled trial showing improvement in pain control with fewer side effects. This study compared the use of combination of both gabapentin and ropivacaine injected to trigger points and gabapentin alone [18].

\subsubsection{Baclofen}

Baclofen is used to control the symptoms in MS, and therefore, it is generally accepted to use in TN patients with MS [59]. It may well control the symptoms without adding carbamazepine. Its side effects including sedation and loss of muscle tone and abrupt discontinuation may cause seizures and hallucinations.

\subsubsection{Lamotrigine}

Lamotrigine is used when Carbamazepine is not tolerated well, or it is used in addition to carbamazepine when it is not effective on its own. There is not enough evidence to support the use of lamotrigine from studies carried out with relation to patients with TN [18].

\subsubsection{Evolving Medical Therapy}

Due to the known difficulty in treating trigeminal neuralgia, new therapeutic modalities are being investigated and have been tried [57]. It has been evident from recent reviews [18] that the combination of the pharmacological drug gabapentin with the addition of regular ropivacaine injections into specific sites, which may be 'trigger sites,' has had a positive outcome on pain control with an improvement in quality of life.

Botulinum Toxin A (BTX-A) has also been suggested as an effective treatment of trigeminal neuralgia from a systematic review [69] carried out on patients suffering from this condition. No major adverse events were reported, and it was concluded that with an approximate $60-80 \%$ reduction in mean pain intensity and frequency, this medical treatment may be a future recommendation. Cruccu and Truini [42] were in agreement with these findings who have also reviewed the literature on possible medical treatments for
Trigeminal Neuralgia. It was highlighted that there is possible increasing evidence for BTX-A injections as a treatment option, specifically prior to considering surgical options or for patients who do not want surgery. In relation to this, it is emphasised that further evidence is needed with regard to this treatment option with more investigation and welldesigned studies to take place.

Finally, it has been highlighted that local anaesthesia injected into the specific trigger area, $8 \%$ lidocaine spray and the use of intravenous infusion of fosphenytoin may be an option to provide temporary relief for patients suffering from severe pain [18].

\subsubsection{Surgical Management}

A successful surgical intervention of $\mathrm{TN}$ is determined by elimination of pain. Currently available surgical options are

1. Invasive technique:

(a) Open:

(i) Microvascular decompression

(b) Percutaneous:

(i) Radiofrequency rhizotomy

(ii) Retrogasserian glycerol rhizotomy

(iii) Balloon compression of trigeminal nerve

(iv) Stereotactic radiosurgery-Gamma knife

2. Non-invasive technique:

(i) Peripheral neurectomy

(ii) Alcohol injections

(iii) Cryotherapy

(iv) Selective radiofrequency thermocoagulation

\subsubsection{Microvascular Decompression (MVD)}

The original theory was outlined by Dandy in 1925, and vascular decompression of the trigeminal nerve was first described by Gardner and Miklos in 1959 [70] and was further refined by Jannetta et al. in 1967 [71]. Advances in anaesthesiology, use of operating microscopes and evolving surgical techniques allowed the MVD as a safer and effective procedure. MVD further evolved in the next 50 years to become accepted as one of the best surgical options.

Surgical target is the trigeminal nerve-pons junction. To reach this target, the posterior cranial fossa needs to be accessed via suboccipital craniotomy. On entering via craniotomy site, cerebrospinal fluid will be aspirated. Further advancing is done towards the nerve by gently retracting part of the cerebellum (Fig. 26.3). It is common to find a segment of superior cerebellar artery compressing on the REZ. Less 


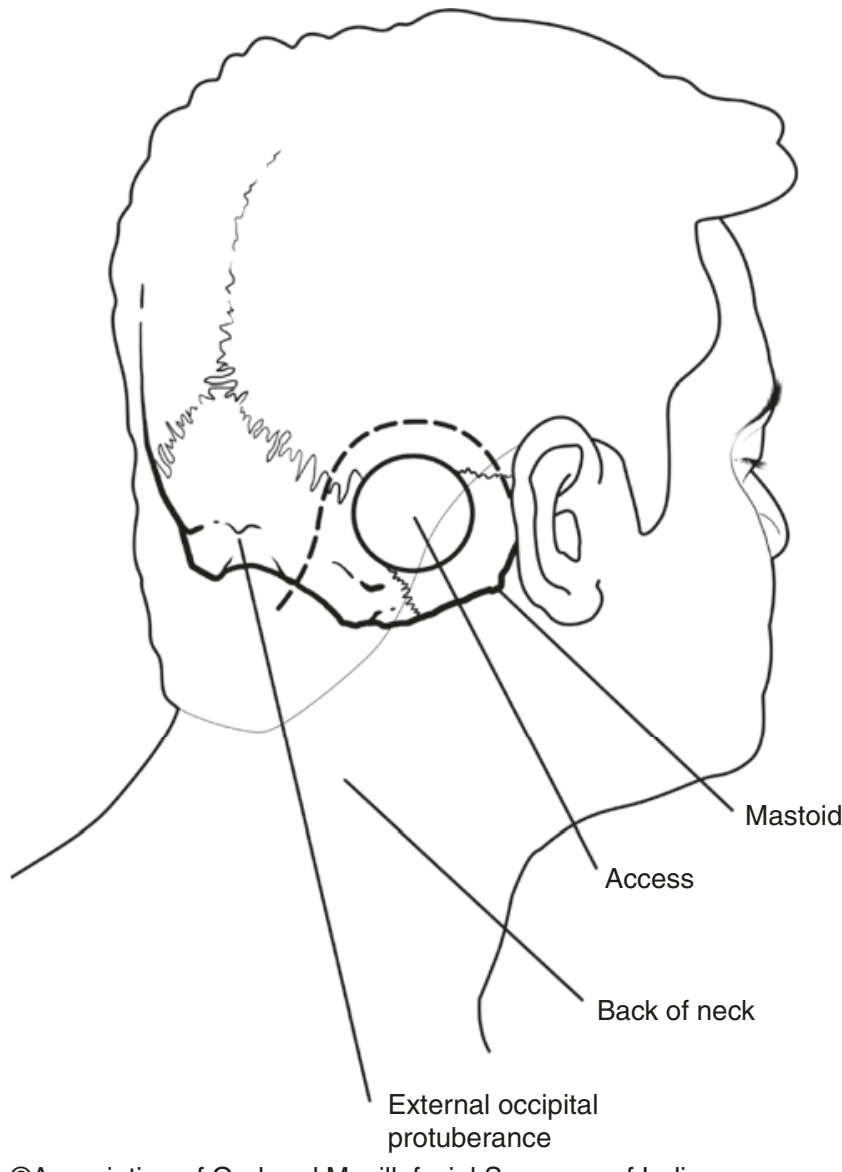

CAssociation of Oral and Maxillofacial Surgeons of India

Fig. 26.3 Diagram showing suboccipital access

commonly, a variation with an anterior inferior cerebellar artery or the superior petrosal vein can be found as a cause of the neurovascular compression [72]. Once the vessel is freed of the REZ, a piece of Teflon is placed to keep the nerve and the vessel apart (Fig. 26.4).

Utmost care should be taken to avoid any post-operative hearing loss. This is usually done by monitoring the brainstem evoked potential as hearing loss is due to the pressure on the eight cranial nerve due to retraction. A timely release of retraction improves this and literature recommends the removal of a section of the root when there is no vascular compression or there may be difficulties in mobilizing the artery. Deliberate Bruising of the nerve in addition to decompression is also recommended [73].

Literature shows that MVD can be done in any age group. Both Resnick et al. and Roski et al. concluded that MVD can be done with good outcomes in the paediatric population $[74,75]$. It is also unique that in the paediatric population, venous compression is more common than arterial.

The long-term outcome of MVD for TN suggests $87-98 \%$ have immediate pain relief but this is reduced slightly to

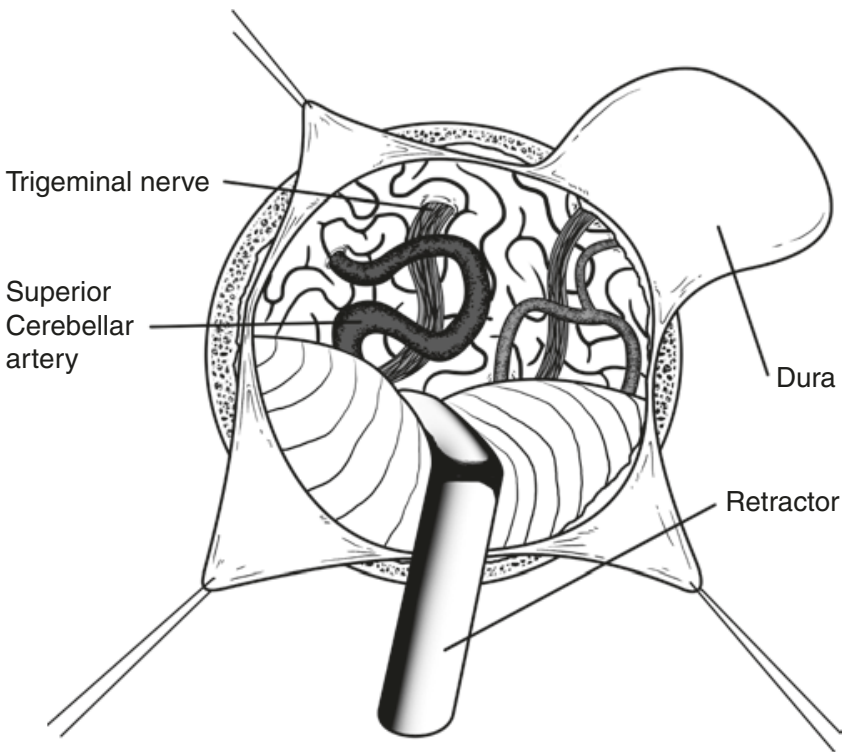

CAssociation of Oral and Maxillofacial Surgeons of India

Fig. 26.4 Craniotomy access showing a retracted and a cerebellar artery resting on the nerve. A piece of Teflon to be placed between the vessel and the nerve

$75-80 \%$ in a 1-2 year review [76-82]. This proportion of patients with pain relief further reduced to $58-64 \%$ this is also associated with $4-12 \%$ of recurrence.

Several studies showed that the outcome of MVD is better with an arterial compression compared to venous [77, 79,83 ]. Lee et al. showed a recurrence rate of $31 \%$ when there is TN due to venous compression and mostly recurred within the first 12 months [83]. Literature shows that there are poor outcomes on patients who have had previous neurosablative surgery, but this is not substantiated by other studies $[76,84,85]$. Review of literature in the management of recurrence following MVD in TN did not provide a general consensus but suggested re-exploration and neuroablative procedures [86-88]. A good quality imaging system may enable the surgeon to pinpoint the reason for the recurrence and choose an appropriate remedial surgical intervention.

In terms of the outcomes, complication rates seem to be minimal with an experienced neurosurgical team with innovations. Although a rate of $0.2-1 \%$ mortality is shown in the earlier literature, two large studies with a patient population of 444 [79] and 1995 [52] showed 0\% mortality. A recent retrospective study listed other complications such as cerebellar injury $(0.45 \%)$ 8th cranial nerve injury $(0.8 \%)$ and CSF leak (1.85\%) [52].

Although this study showed low complication rates, other centres reported higher complication rates [80, 81]. This wide range in the outcomes is likely due to the experience of the surgical team and their advanced perioperative monitoring systems. 
Despite the increasing popularity of MVD, its advantage over the neuroablative procedures continues to be debated at various levels $[22,89]$. In the absence of well-structured clinical studies, varying interventions will be preferred based on the individual centre experience.

\subsubsection{Gamma Knife Radiosurgery (GKRS)}

In the 1950s, the term and the concept of radiosurgery and Gamma Knife were introduced by Lars Leksell. GKRS is used to treat various benign and malignant brain tumours and also various non-neoplastic conditions such as vascular malformations without an open intracranial surgical access. For the next few decades, GKRS is evolved with technology as the precision targeting has improved [90]. The 'Gamma Knife' technique was based on the fact that radiation may block the conduction of excessive sensory information responsible for triggering the pain episodes [91]. This would affect the radiosurgery targets with no significant change outside the target nerve, with the myelin sheath being primarily affected by radiosurgery [92]. It is indicated in typical or atypical TN, with or without vascular compression, failed MVD, TN patients in MS and patients with significant medical comorbidities.

This procedure [90-92] is done under local anaesthetic with or without sedation. Once the patient is supine under the collimator head, local anaesthetic is used to secure the stereotactic frame to the patient's head. MRI is then performed to locate the trigeminal nerve. Gamma knife is made up of 201 intercepting beams of gamma radiation with a dose of 70-100 Gy, and it is targeted at REZ of trigeminal nerve. Radiosurgery can be done with or without frame-based method, with MRI or computerized tomography (CT) planning when there is contraindication to MRI.

GKRS can also be given using one or two isocenters/target areas and targeting radiosurgery posteriorly at dorsal REZ or anteriorly in retrogasserian zone. Lower dosages to the root can be associated with fewer side effects, whereas higher dosages provide better pain control with less risk of recurrence but more side effects such as facial numbness. The benefits and risks of a higher dose must be carefully discussed with patients since bothersome facial numbness may be an acceptable option for patients with severe pain.

Two studies showed that approximately it takes a month for pain relief [91]. One of them is a multicentre study of 50 patients with a median follow-up of 18 months, which showed the results of 58\% pain free and $36 \%$ had significant pain relief with a $6 \%$ failure rate.

However, when recurrence is evident after GKRS, repeat GKRS provides a similar rate of pain relief as the first procedure. The best responses are observed when there is good pain control after first procedure, with new sensory dysfunction and in single division nerve distribution typical TN.

\subsubsection{Percutaneous Balloon Compression (PBC)}

PBC was described by Mullen in 1980 [93]. It relieves TN pain by injuring the large myelinated fibres involved in the sensory trigger. It is especially useful in managing TN with first division involvement as it selectively spares small myelinated fibres, which mediate the corneal/blink reflex. It gained its role in management of $\mathrm{TN}$ due to its low cost and simplicity.

The procedure is performed under a short general anaesthetic, with a fluoroscopic control. A 14-gauge cannula is inserted into foramen ovale but does not pass beyond. A negative cerebrospinal fluid confirms it further. A catheter advanced through the needle, and balloon inflated slowly up to a pressure of 1.3-1.6 atm. Balloon can also be inflated with $0.5-1.0 \mathrm{ml}$ of contrast dye until it occupies Meckel's cave, and radiographic confirmation of its position is achieved. Up to 6 min of duration of compression is achieved. Typically, patients awaken with a mild subjective sensory loss with immediate pain relief up to $80-90 \%[94,95]$. This subjective numbness resolves in few weeks.

PBC is most helpful when pain involves multiple divisions including the first division, patients with MS, significant comorbidities and failed MVD.

\subsubsection{Radiofrequency Thermocoagulation (RFTC)}

Failures and complications in failing to control the spread of alcohol in ganglionolysis led to thermocoagulation of the Gasserian ganglion. This procedure thermocoagulates the ganglion at temperatures above $65{ }^{\circ} \mathrm{C}$, which selectively ablates the $\mathrm{A} \delta$ and $\mathrm{C}$ pain fibres $[96,97]$.

The procedure is carried out under a short-intermittent general anaesthesia either under fluoroscopic control or radiologically guided. Patients are awake for the part of the procedure to ensure correct positioning of the needle. The radiofrequency needle with a stylet is introduced through the foramen ovale into Meckel's cave using bony landmarks. Transient bradycardia may occur at this juncture. Once the needle position at the trigeminal rootlet is confirmed by fluoroscopy and radiographs, the stylet can be removed to introduce the electrocoagulation needle. The patient is awakened, and the stimulation of the nerve root can be tested. A mapping of the paraesthesia is carried out to the trigger zones of the neuralgia. Then, the patient is anaesthetized again for thermocoagulation, which is achieved with $0.2-1 \mathrm{~V}$. The same procedure is repeated for 45-90s cycles at temperatures of $60-90{ }^{\circ} \mathrm{C}$. After each episode of thermocoagulation, the patient is awakened and the sensory mapping is repeated again [19]. 


\subsubsection{Glycerol Rhizotomy}

This procedure was a chance finding by Håkansson and colleagues whilst working on stereotactic gamma radiation for TN. They used glycerol mixed with tantalum dust as a radio-opaque marker to visualize the trigeminal cistern and discovered that it also abolished pain. They published the first series of 75 patients with a mean follow-up of 18 months [98].

This procedure is done under local anaesthesia with sedation. Similar to other percutaneous in the treatment of TN, the aim is to safely place the needle at the gasserian ganglion [99]. The advantage of being done awake allows the patient to sit up, and a small dose of sterile glycerol is injected in small increments. Up to a total of $0.1-0.4 \mathrm{ml}$ can be used based on the number of divisions involved. Patients remain seated for up to $2 \mathrm{~h}$ to allow glycerol to reach the intended root.

This method is well tolerated with negligible mortality. Commonly reported complications are meningitis, cranial nerve palsies, local haematomas, reactivation of herpes labialis and permanent masseter weakness [100].

\subsection{Peripheral Nerve Procedures}

\subsubsection{Infraorbital Neurectomy}

Peripheral neurectomies are a safe and cost-effective option for patients with medical co-morbidities, elderly and for population where there is lack of highly skilled neurosurgical centres. Pain relief can be lasting from 15 to 24 months. Loss of sensation and recurrences are associated with peripheral neurectomy. These are carried out by oral and maxillofacial surgeons, and it is under reported to evaluate its benefits over central neurosurgical interventions.

Access to infraorbital nerve is gained through a maxillary vestibular approach. The infraorbital foramen is identified as it is exiting foramen and the nerve is released from the foramen by raising the periosteum around it. Care should be taken as to ensure that there is no 'pull' to trunk of the nerve from the infraorbital canal. Reeling of the nerve is also a common practice, but sectioning of the nerve is done to eliminate the touch sensation, and there is no need to remove the infraorbital canal portion of the nerve.

The nerve is then sectioned using diathermy to have a bloodless field and nerve branches on the soft tissue side may be closed over by releasing the surrounding periosteum to avoid regeneration. Similarly, infraorbital canal can be obturated with bone wax or chips of the bone carved around the canal.

Khanna and Galinde [101] published their successful experience of 118 patients with $75 \%$ pain relief at a 1-5 year follow-up.
Oturi et al. published their 7 years follow-up series comparing alcohol block, neurectomy and thermocoagulation. They have found that up to $78 \%$ had recurrence with the neurectomy cohort, and sadly, one of half of it recurred within a month. They reported the complications rate under $10 \%$ (dysesthesia and eye problems) on thermocoagulation and alcohol ganglionolysis patients [102].

\subsubsection{Inferior Alveolar Nerve or Mental Nerve Neurectomy}

Ali FM et al. [103] suggest peripheral neurectomy in a rural set-up where there is a lack of highly trained and equipped neurosurgical facilities. It is an effective option for elderly patients and who are reluctant for opting for neurosurgical intervention.

\subsubsection{Inferior Alveolar Neurectomy via Ginwala's Access [103] (Video 26.1)}

This procedure is done under local anaesthesia, with access gained to the medial aspect of the ramus using an inverted Y-shaped incision. Once the incision is made, the mucoperiosteal flap is raised along the anterior aspect of the ramus. The tendon of the temporalis and the medial pterygoid muscle is raised off the bone for access to the lingula and once the inferior alveolar nerve is dissected free off the surrounding tissues, the neurovascular bundle is clamped and cut below the clamp by electrocoagulation to achieve haemostasis. Following this, a separate buccal sulcus incision is made to identify the mental foramen and the end of inferior vascular bundle is identified and dissected off the surrounding tissues. The bundle is then clamped and sectioned to avulse the neurovascular bundle from the canal.

Based on the available literature, there is a role for peripheral neurectomy in selective cases where other treatments have failed, and in patients with comorbidities and where there is reluctancy of either clinician or the patient to opt for neurosurgical procedures. However, it is difficult to conclude its role as a primary interventional procedure.

\subsubsection{Cryotherapy}

Peripheral procedures in the management of TN result in permanent sensory loss with the aim of achieving pain free results, and therefore, alternative forms were sought. Cryofreezing is performed on the surgically exposed nerve endings with temperatures of -50 to $-70{ }^{\circ} \mathrm{C}$ [104]. Literature shows that this procedure is well tolerated by the patients; however, the results are sub-optimal. In a study published in 1988, 145 patients underwent 348 sessions of which $56 \%$ 
had more than one session. The pain-free effect lasted less than 6 months in one half of patients, and at 12 months, only $27 \%$ were pain-free [105]. It is also important to note that $61 \%$ of the patients remained on their previous medications. The treatment it is well tolerated by the patients and were willing to undergo repeated cryofreezing and the distinct advantage is that the nerve damage is reversible. It is likely that adjacent nerve branch reconnecting is the reason for the recurrence of the pain. Although the sensation is preserved and nerve injury is reversible, its outcomes fall short of other peripheral procedures. It is reported that $4 \%$ of the patients developed post-operative infections warranting antibiotic therapy and about $40 \%$ had suffered, some from pain ranging from burning sensation, pins and needles to symptoms such as a dull ache [105].

In summary, despite patient outcomes with this procedure and preserved sensation, there is little evidence to support this procedure in the role of management of $\mathrm{TN}$ where other surgical procedures are available.

\subsubsection{Alcohol Block}

Percutaneous ganglionic ganglionic blocks and peripheral blocks have been used since the 1930s. Direct deposition of alcohol into the affected nerve peripheral branch causes chemical ablation of the nerve. Essentially, alcohol causes destruction of nerve fibres. It can seep into the adjacent tissues and cause necrosis, resulting in pain and local oedema. With a high-risk recurrence of pain and with a moderate risk of developing dysesthesia, its use is restricted only in the elderly or patients with comorbidities or those who are reluctant to undergo extensive neurosurgical procedures.

An injection of $0.5-1.0 \mathrm{ml}$ of absolute alcohol is injected directly into the affected nerve bundle under local anaesthesia and injections have to be placed accurately to avoid dissipation, which may result in local damage. Utmost care must be taken to avoid intravascular injections and not to inject into the subcutaneous tissues [106].

The duration of pain relief varies from 6 to 24 months, and there is variation with different peripheral branches. Only a short pain relief with third division is observed compared to the second with a longer duration of pain relief with in the first division [106].

\subsubsection{Other Peripheral Procedures}

Other peripheral neurolysis procedures seen in the literature are radiofrequency coagulation and chemical neurolysis with glycerol, phenol, mixture of lignocaine with streptomycin and high concentration of tetracaine. Evidence in the litera- ture fails to support their true efficacy and long-term benefits.

\subsection{Conclusion}

$\mathrm{TN}$ is the most severe type of pain humans ever face for an innocuous touch without any force, and it is debilitating to an extent that it was described historically as "suicide disease" until the development of the medications and various surgical procedures in the 1950s.

As an OMF surgeon, obtaining a good clinical history is to rule out other potential pathologys including dental focus. Patients may be initially present to a primary care dentist or a physician with facial pain, and they should be aware of the medical management and the secondary care team (oral medicine specialists, OMFS and neurologists) involved to deliver the appropriate course of action. Usually, only those who are refractory to the drug therapy or unacceptable drug-related side effects will be escalated further to tertiary care for the consideration of complex central surgical procedure.

Peripheral surgical procedures are suitable for those who are unable or unwilling to undergo complex and expensive neurosurgical procedures. Peripheral procedures are safe with minimal morbidity and almost no mortality; however, there is a lack of evidence to show the recurrence rate and associated long-term complications.

The management of TN patients should be carried out in a multidisciplinary setting to allow the patients to choose the best-suited option for them. It is also important to set up selfhelp groups to enable them to share knowledge and information for themselves and their family members for the best possible outcomes.

\section{References}

1. Joo W, Yoshioka F, Funaki T, Mizokami K, Rhoton AL Jr. Microsurgical anatomy of the trigeminal nerve. Clin Anat. 2014;27:61-88.

2. Haller S, Etienne L, Kovari E, Varoquax AD, Urbach H, Becker $\mathrm{M}$. Imaging of neurovascular compression syndromes: trigeminal neuralgia, hemifacial spasm, vestibular paroxysmia, and glossopharyngeal neuralgia. AJNR Am J Neuroradiol. 2016;37:1384-92.

3. Sindou M, Howeidy T, Acevedo G. Anatomical observations during microvascular decompression for idiopathic trigeminal neuralgia (with correlations between topography of pain and site of the neurovascular conflict): prospective study in a series of 579 patients. Acta Neurochir. 2002;144:1-12.

4. Harris W. Rare forms of paroxysmal trigeminal neuralgia, and their relation to disseminated sclerosis. Br Med J. 1950;2:1015-9.

5. Foley PL, Vesterinen HM, Laird BJ, Sena ES, Colvin LA, Chandran S, et al. Prevalence and natural history of pain in adults with multiple sclerosis: systematic review and meta-analysis. Pain. 2013;154:632-42. 
6. Toda K. Aetiology of trigeminal neuralgia. Oral Sci Int. 2007;4:10-8.

7. Mohammad-Mohammadi A, Recinos PF, Lee JH, Elson P, Barnett GH. Surgical outcomes of trigeminal neuralgia in patients with multiple sclerosis. Neurosurgery. 2013;73:941-50.

8. Zakrzewska J, Jianhua WU, Tricia S, Brathwaite L-A. Systematic review of the management of trigeminal neuralgia in patients with multiple sclerosis. World Neurosurg. 2018;111:291-306.

9. Cruccu G, Biasiotta A, Di RS, Fiorelli M, Galeotti F, Innocenti P, et al. Trigeminal neuralgia and pain related to multiple sclerosis. Pain. 2009;143:186-91.

10. Reder AT, Arnason BG. Trigeminal neuralgia in multiple sclerosis relieved by a prostaglandin $\mathrm{E}$ analogue. Neurology. 1995;45:1097-100.

11. Tesfaye S, Selvarajah D. Advances in the epidemiology, pathogenesis and management of diabetic peripheral neuropathy. Diabetes Metab Res Rev. 2012;38:8-14.

12. Xu Z, Zhang P, Long L, He H, Zhang J, Sun S. Diabetes mellitus in classical trigeminal neuralgia: a predisposing factor for its development. Clin Neurol Neurosurg. 2016;151:70-2.

13. NICE. NICE Guidance (online). 2017. Available at http://guidance.nice.org.uk/CG173

14. Dworkin RH, Nagasako EM, Johnson RW, Griffin DR. Acute pain in herpes zoster: the famciclovir database project. Pain. 2001;94:113-9.

15. Beutner KR, Friedman DJ, Forszpaniak C, Andersen PL, Wood MJ. Valaciclovir compared with aciclovir for improved therapy for herpes zoster in immunocompetent adults. Antimicrob Agents Chemother. 1995;39:1546-53.

16. Davis LE, King MK. Shingles (herpes zoster) and post-herpetic neuralgia. Curr Treat Options Neurol. 2001;3:401-11.

17. Schmader K. Herpes zoster in older adults. Clin Infect Dis. 2001;32:1481-6.

18. Zakrzewska JM, Linskey ME. Trigeminal neuralgia. BMJ Clin Evid. 2014;10:1207.

19. Nurmikko TJ, Eldridge PR. Trigeminal neuralgia-pathophysiology, diagnosis and current treatment. $\mathrm{Br} \mathrm{J}$ Anaesth. 2001;87:117-32.

20. Amir R, Michaelis M, Devor M. Membrane potential oscillations in dorsal root ganglion neurons: role in normal electrogenesis and neuropathic pain. J Neurosci. 1999;19:89-96.

21. Rappaport ZH, Devor M. Trigeminal neuralgia: the role of self-sustaining discharge in the trigeminal ganglion. Pain. 1994;56:127-38.

22. Taha JM, Tew JM, Buncher CR. A prospective 15-year follow up of 154 consecutive patients with trigeminal neuralgia treated by percutaneous stereotactic radiofrequency thermal rhizotomy. J Neurosurg. 1995;83:989-93.

23. Rose FC. Trigeminal neuralgia. Arch Neurol. 1999;56:1163-4.

24. Amir R, Devor M. Functional cross-excitation between afferent A- and C-neurons in dorsal root ganglia. Neuroscience. 2000;95:189-95.

25. Harris W. The facial neuralgias. London: Oxford University Press; 1937. p. 13-4.

26. Pearce JMS. HISTORICAL NOTE-Trigeminal neuralgia (Fothergill's disease) in the 17th and 18th centuries. J Neurol Neurosurg Psychiatry. 2003;74:1688.

27. André N. Traité sur les maladies de l'urèthre. Paris: Delaguette; 1756.

28. Fromm GH, Sessle BJ. Introduction and historical review. In: Fromm GH, Sessle B, editors. Trigeminal neuralgia: Current concepts regarding pathogenesis and treatment. Boston: ButterworthHeinemann; 1991. p. 1-26.

29. Dandy WE. Section of sensory root of the trigeminal nerve at the pons. Bull Johns Hopkins Hosp. 1925;36:105.
30. Gardner WJ, Miklos MV. Response of trigeminal neuralgia to 'decompression' of sensory root: discussion of cause of trigeminal neuralgia. JAMA. 1959;170:1773-6.

31. Jannetta PJ. Treatment of trigeminal neuralgia by suboccipital and transtentorial cranial operation. Clin Neurosurg. 1977;24:538-49.

32. Bergouignan M. Cures heureuses de ne Âvralgies faciales essentielles par le diphennyl-hydantoinate de soude. Rev Laryngol Otol Rhinol (Bord). 1942;63:34-41.

33. MacDonald BK, Cockerell OC, Sander JW, Shorvon SD. The incidence and lifetime prevalence of neurological disorders in a prospective community-based study in the UK. Brain. 2000;123(Pt 4):665-76.

34. Katusic S, Beard CM, Bergstralh E, Kurland LT. Incidence and clinical features of trigeminal neuralgia, Rochester, Minnesota, 1945-1984. Ann Neurol. 1990;27:89-95.

35. Katusic S, Williams DB, Beard CM, Bergstralh EJ, Kurland LT. Epidemiology and clinical features of idiopathic trigeminal neuralgia and glossopharyngeal neuralgia: similarities and differences, Rochester, Minnesota, 1945-1984. Neuroepidemiology. 1991;10:276-81.

36. Zakrzewska JM. Trigeminal neuralgia. Clin Evid. 2003;9:1490-8.

37. White JC, Sweet WH. Pain and the neurosurgeon: a 40-year experience. Springfield, IL: Charles C Thomas; 1969. p. 123-5.

38. Coulthard P, Horner K, Sloan P, Theaker E. Facial pain, oral and maxillofacial surgery, radiology, pathology and oral medicine, Second Edition Master Dentistry Volume One, Edinburgh: Churchill Livingstone Elsevier, Chapter 14. pp. 228-9; 2008.

39. De Toledo I, Conti Réus J, Fernandes M, Porporatti A, Peres M, Takaschima A, Linhares M, Guerra E, De Luca Canto G. Prevalence of trigeminal neuralgia-A systematic review. J Am Dent Assoc. 2016;147(7):570-6.

40. Lu VM, Goyal A, Graffeo CS, Perry A, Jonker BP, Link MJ. Glossopharyngeal neuralgia treatment outcomes after nerve section, microvascular decompression, or stereotactic radiosurgery: a systematic review and meta-analysis. World Neurosurg. 2018;120:572-82.

41. Headache Classification Committee of the International Headache Society (IHS). The International Classification of Headache Disorders, 3rd edition. Cephalalgia. 2018;38:1-211.

42. Di Stefano G, Truini A, G. Cruccu current and innovative pharmacological options to treat typical and atypical trigeminal neuralgia. Drugs. 2018;78:1433-42.

43. Meaney JF, Miles JB, Nixon TE, Whitehouse GH, Ballantyne ES, Eldridge PR. Vascular contact with the fifth cranial nerve at the pons in patients with trigeminal neuralgia: detection with 3D FISP imaging. Am J Roentgenol. 1994;163:1447-52.

44. Meaney JF, Eldridge PR, Dunn LT, Nixon TE, Whitehouse GH, Miles JB. Demonstration of neurovascular compression in trigeminal neuralgia with magnetic resonance imaging: comparison with surgical findings in 52 consecutive operative cases. J Neurosurg. 1995;83:799-805.

45. Masur H, Papke K, Bongartz G, Vollbrecht K. The significance of three-dimensional MR-defined neurovascular compression for the pathogenesis of trigeminal neuralgia. J Neurol. 1995;242:93-8.

46. Korogi Y, Nagahiro S, Du C, et al. Evaluation of vascular compression in trigeminal neuralgia by $3 \mathrm{D}$ time-of-flight MRA. J Comput Assist Tomogr. 1995;19:879-84.

47. Majoie CB, Hulsmans FJ, Castelijns JA, et al. Symptoms and signs related to the trigeminal nerve: diagnostic yield of MR imaging. Radiology. 1998;209:557-62.

48. Boecher-Schwarz HG, Bruehl K, Kessel G, Guenthner M, Perneczky A, Stoeter P. Sensitivity and specificity of MRA in the diagnosis of neurovascular compression in patients with trigeminal neuralgia: a correlation of MRA and surgical findings. Neuroradiology. 1998;40:88-95. 
49. Jawahar A, Kondziolka D, Kanal E, Bissonette DJ, Lunsford LD. Imaging the trigeminal nerve and pons before and after surgical intervention for trigeminal neuralgia. Neurosurgery. 2001;48:101-6.

50. Patel NK, Aquilina K, Clarke Y, Renowden SA, Coakham HB. How accurate is magnetic resonance angiography in predicting neurovascular compression in patients with trigeminal neuralgia? A prospective, single-blinded comparative study. Br J Neurosurg. 2003;17:60-4.

51. Jannetta PJ. Neurovascular compression in cranial nerve and systemic disease. Ann Surg. 1980;192:518-25.

52. McLaughlin MR, Jannetta PJ, Clyde BL, Subach BR, Comey CH, Resnick DK. Microvascular decompression of cranial nerves: lessons learned after 4400 operations. J Neurosurg. 1999;90:1-8.

53. Love S, Coakham HB. Trigeminal neuralgia: pathology and pathogenesis. Brain. 2001;124:2347-60.

54. Zakrzewska JM. Diagnosis and differential diagnosis of trigeminal neuralgia. Clin J Pain. 2002;18:14-21.

55. Meaney JF, Watt JW, Eldridge PR, Whitehouse GH, Wells JC, Miles JB. Association between trigeminal neuralgia and multiple sclerosis: role of magnetic resonance imaging. J Neurol Neurosurg Psychiatry. 1995;59:253-9.

56. Montano N, Conforti G, Di Bonaventura R, Meglio M, Fernandez E, Papacci F. Advances in diagnosis and treatment of trigeminal neuralgia. Ther Clin Risk Manag. 2015;11:289-99.

57. Cruccu G, Gronseth G, Alksne J, Argoff C, Brainin M, Burchiel K, Nurmikko T, Zakrzewska J. AAN-EFNS guidelines on trigeminal neuralgia management. Eur J Neurol. 2008;15(10):1013-28.

58. Zakrzewska JM. Trigeminal neuralgia. In: Clinical evidence. Issue 7. London: BMJ Publishing; 2002. p. 1221-31.

59. Fromm GH. Baclofen as an adjuvant analgesic. J Pain Symptom Manag. 1994;9:500-9.

60. Wiffen P, Collins S, McQuay H, Carroll D, Jadad A, Moore A. Anticonvulsant drugs for acute and chronic pain. Cochrane Database Syst Rev. 2000;3:CD001133.

61. Wiffen P, McQuay H, Moore R. Carbamazepine for acute and chronic pain. Cochrane Database Syst Rev. 2005;3:CD005451.

62. Jensen TS. Anticonvulsants in neuropathic pain: rationale and clinical evidence. Eur J Pain. 2002;6(Suppl A):61-8.

63. Killian JM, Fromm GH. Carbamazepine in the treatment of neuralgia. Use of side effects. Arch Neurol. 1968;19(2):129-36.

64. Nicol CF. A four-year double-blind study of tegretol in facial pain. Headache. 1969;9(1):54-7.

65. Rockliff BW, Davis EH. Controlled sequential trials of carbamazepine in trigeminal neuralgia. Arch Neurol. 1996;15(2):129-36.

66. Wiffen PJ, Derry S, Moore RA, Kalso EA. Carbamazepine for chronic neuropathic pain and fibromyalgia in adults. Cochrane Database Syst Rev. 2014;4:CD005451.

67. McQuay H, Carroll D, Jadad AR, Wiffen P, Moore A. Anticonvulsant drugs for management of pain: a systematic review. BMJ. 1995;311(7012):1047-52.

68. Kutluay E, McCague K, D’Souza J, Beydoun A. Safety and tolerability of oxcarbazepine in elderly patients with epilepsy. Epilepsy Behav. 2003;4(2):175-80.

69. Hu Y, Guan X, Fan L, et al. Therapeutic efficacy and safety of botulinum toxin type $\mathrm{A}$ in trigeminal neuralgia: a systematic review. J Headache Pain. 2013;14:72.

70. Gardner WJ, Miklos MV. Response of trigeminal neuralgia to decompression of sensory root: discussion of cause of trigeminal neuralgia. J Am Med Assoc. 1959;170:1773-6.

71. Jannetta PJ. Arterial compression of the trigeminal nerve at the pons in patients with trigeminal neuralgia. J Neurosurg. 1967;26:159-62.
72. Rhoton AL. The cerebellopontine angle and posterior fossa cranial nerves by the retrosigmoid approach. Neurosurgery. 2000;47(Suppl):S93-129.

73. Adams CBT. Trigeminal neuralgia: pathogenesis and treatment Br J Neurosurg. 1997;11:493-5.

74. Resnick DK, Levu EI, Jannetta PJ. Microvascular decompression for paediatric onset trigeminal neuralgia. Neurosurgery. 1998;43:804-8.

75. Roski RA, Horwitz SJ, Spetzler RF. Atypical trigeminal neuralgia in a 6-year-old boy. J Neurosurg. 1982;5:424-5.

76. Barker FG, Jannette PJ, Bissonette DJ, Larkins MV, Jho HD. The long-term outcome of microvascular decompression for trigeminal neuralgia. N Engl J Med. 1996;334:1077-83.

77. Burchiel KJ, Clarke H, Haglund M, Loeser JD. Long-term efficacy of microvascular decompression in trigeminal neuralgia. J Neurosurg. 1988;69:35-8.

78. Kolluri S, Heros RC. Microvascular decompression for trigeminal neuralgia. A five-year follow-up study. Surg Neurol. 1984;22:235-40.

79. Kondo A. Follow-up results of microvascular decompression in trigeminal neuralgia and hemifacial spasm. Neurosurgery. 1997;40:46-52.

80. Lee KH, Chang JW, Park YG, Chung SS. Microvascular decompression and percutaneous rhizotomy in trigeminal neuralgia. Stereotact Funct Neurosurg. 1997;68:196-9.

81. Platt JH, Wilkins RH. Treatment of tic douloureux and hemifacial spasm by posterior fossa exploration: therapeutic implications of various neurovascular relationships. Neurosurgery. 1984;14:462-71.

82. Sletteb $\varnothing$ HJ, Eide PK. A prospective study of microvascular decompression for trigeminal neuralgia. Acta Neurochir. 1997;139:421-5.

83. Lee SH, Levy EI, Scarrow AM, Kassam A, Jannetta PJ. Recurrent trigeminal neuralgia attributable to veins after microvascular decompression. Neurosurgery. 2000;46:352-6.

84. Barba D, Alksne JF. Success of microvascular decompression with and without prior surgical therapy for trigeminal neuralgia. J Neurosurg. 1984;60:104-7.

85. Hunn MK, Eldridge PR, Miles JB, West B. Persistent facial pain following microvascular decompression of the trigeminal nerve. Br J Neurosurg. 1998;12:23-8.

86. Kureshi SA, Wilkins RH. Posterior fossa exploration for persistent or recurrent trigeminal neuralgia or hemifacial spasm: surgical findings and therapeutic implications. Neurosurgery. 1998;43:1111-7.

87. Liao J-J, Cheng W-C, Chang C-N, Wei K-C, Hsu Y-H, Lin $\mathrm{T}-\mathrm{K}$. Reoperation for recurrent trigeminal neuralgia after microvascular decompression. Surg Neurol. 1997;47:562-70.

88. Rath SA, Klein HJ, Richter H-P. Findings and long-term results of subsequent operations after failed microvascular decompression for trigeminal neuralgia. Neurosurgery. 1996;39:933-40.

89. Kitt CA, Gruber K, Davis M, Woolf CJ, Levine JD. Trigeminal neuralgia: opportunities for research and treatment. Pain. 2000;85:3-7.

90. Kondziolka D. Functional neurosurgery. Neurosurgery. 1999;44:12-20.

91. Kondziolka D, Lunsford LD, Flickinger JC, Young R, Vermeulen S, Duma C, Jacques D, Rand RW, Regis J, Peragut JC, Manera L, Epstein M, Lindquist C. Steretotactic radiosurgery for trigeminal neuralgia: a multi-institution study using the gamma unit. $\mathrm{J}$ Neurosurg. 1996;84:940-5.

92. Kondziolka D, Perez P, Flickinger JC, Habeck M, Lunsford LD. Gamma knife radiosurgery for trigeminal neuralgia. Arch Neurol. 1998;55:1524-9. 
93. Mullan S, Duda EE, Patronas NJ. Some examples of balloon technology in neurosurgery. J Neurosurg. 1980;52(3):321-9.

94. Tatli M, Satici O, Kanpolat Y, Sindou M. Various surgical modalities for trigeminal neuralgia: literature study of respective longterm outcomes. Acta Neurochir. 2008;150(3):243-55.

95. Bergenheim AT, Asplund P. Linderoth B percutaneous retrogasserian balloon compression for trigeminal neuralgia: review of critical technical details and outcomes. World Neurosurg. 2013;79(2):359-68.

96. Sweet WG. Proceedings: analgesia dolorosa after differential retrogasserian thermal or mechanical rhizotomy: tactics employed to decrease its influence. J Neurol Neurosurg Psychiatry. 1975;38(4):407.

97. Liu JK, Apfelbaum RI. Treatment of trigeminal neuralgia. Neurosurg Clin N Am. 2004;15(3):319-34.

98. Håkansson S. Trigeminal neuralgia treated by the injection into the trigeminal cistern. Neurosurgery. 1981;9:638-46.

99. Young RF. Glycerol rhizolysis in the treatment of trigeminal neuralgia. J Neurosurg. 1988;69:39-45.

100. North RB, Kidd DH, Piantadosi S, Carson BS. Percutaneous retrogasserian glycerol rhizotomy. Predictors of success and failure in treatment of trigeminal neuralgia. J Neurosurg. 1990;72:851-6.
101. Khanna JN, Galinde JS. Trigeminal neuralgia. Report of 140 cases. Int J Oral Surg. 1985;14(4):325-32.

102. Oturai AB, Jensen K, Erikson J, Marsden F. Neurosurgery for trigeminal neuralgia: comparison of alcohol block, neurectomy and radiofrequency coagulation. Clin J Pain. 1996;12:311-5.

103. Ali FM, Prasant MC, Pai D, Aher VA, Kar S, Safiya T. Peripheral neurectomies: a treatment option for trigeminal neuralgia in rural practice. J Neurosci Rural Pract. 2012;3:152-7.

104. Nally FF. A 22-year study of paroxysmal trigeminal neuralgia in 211 patients with a 3-year appraisal of the role of cryotherapy. Oral Surg. 1984;58:17-23.

105. Zakrzewska JM, Nally FF. The role of cryotherapy (cryoanalgesia) in the management of paroxysmal trigeminal neuralgia: a sixyear experience. Br J Oral Maxillofac Surg. 1988;26:18-25.

106. McLeod NMH, Patton DW. Peripheral alcohol injections in the management of trigeminal neuralgia. Oral Surg Oral Med Oral Pathol Oral Radiol Endod. 2007;104(1):12-7.

Open Access This chapter is licensed under the terms of the Creative Commons Attribution 4.0 International License (http://creativecommons. org/licenses/by/4.0/), which permits use, sharing, adaptation, distribution and reproduction in any medium or format, as long as you give appropriate credit to the original author(s) and the source, provide a link to the Creative Commons license and indicate if changes were made.

The images or other third party material in this chapter are included in the chapter's Creative Commons license, unless indicated otherwise in a credit line to the material. If material is not included in the chapter's Creative Commons license and your intended use is not permitted by statutory regulation or exceeds the permitted use, you will need to obtain permission directly from the copyright holder. 